\title{
Prospective evaluation of computed tomography and mediastinoscopy in mediastinal lymph node staging
}

\author{
A. Gdeedo*, P. Van Schil*, B. Corthouts**, F. Van Mieghem**, \\ J. Van Meerbeeck+, E. Van Marck++
}

Prospective evaluation of computed tomography and mediastinoscopy in mediastinal lymph node staging. A. Gdeedo, P. Van Schil, B. Corthouts, F. Van Mieghem, J. Van Meerbeeck, E. Van Marck. CERS Journals Ltd 1997.

ABSTRACT: Precise mediastinal lymph node (LN) staging is imperative in otherwise operable non-small cell lung cancer (NSCLC), as it determines subsequent treatment and possible inclusion in a neoadjuvant trial. The roles of mediastinoscopy and computed tomography (CT) remain controversial. To determine the accuracy of current CT scanners, a prospective study was performed.

From April 1993 until September 1995, 100 consecutive patients with NSCLC without distant metastases underwent staging by $\mathrm{CT}$ and cervical mediastinoscopy. Naruke's map was used for classification, and LNs larger than $1 \mathrm{~cm}$ were considered CT positive. There were 91 males and 9 females, with a mean age of 64 (range 45-82) yrs. Fifty nine tumours were central and 41 peripheral, 64 right-sided and 36 left-sided. Thoracotomy with mediastinal LN sampling was performed in $\mathbf{7 4}$ patients, nonoperated patients having multilevel stage IIIA or stage IIIB disease.

Twenty five $(25 \%)$ mediastinoscopies were positive and three were false-negative (3\%). There were 29 false-positive CT scans and 12 false-negative. Overall sensitivity and specificity of CT were 63 and $57 \%$, respectively, and of mediastinoscopy 89 and $100 \%$, respectively. Positive and negative predictive values of CT were 41 and $77 \%$, respectively, and of mediastinoscopy 100 and $96 \%$, respectively. Accuracy of CT was $59 \%$ and of mediastinoscopy $97 \%$. Accuracy of CT was lowest for left-sided and centrally located tumours, and for LN station 7.

Even with current computed tomography scanners, sensitivity and specificity remain low. Although overall cost may increase, routine cervical mediastinoscopy is necessary for precise staging of non-small cell lung cancer, and subcarinal lymph nodes should be routinely sampled.

Eur Respir J 1997; 10: 1547-1551.
Depts of *Thoracic Surgery, **Radiology, +Pulmonary Medicine and ++Pathology, University Hospital of Antwerp, Edegem, Belgium.

Correspondence: P. Van Schil

Dept of Surgery

University Hospital of Antwerp

Wilrijkstraat 10

B-2650 Edegem

Belgium

Keywords: Computed tomography

lung cancer (staging)

lymph nodes (mediastinal)

mediastinoscopy

Received: September 21996

Accepted after revision January 221997

Presented as a poster at the ERS Annual Congress in Stockholm, September 1996, in the Session "Surgery for Thoracic Malignancy and its Complications"
Lung cancer continues to be a major health problem. The number of deaths exceeds that of any other cancer site.

Precise staging in otherwise operable non-small cell lung cancer (NSCLC) is imperative in order to establish an adequate treatment plan. Although the stage of the primary tumour strongly influences the local resectability of the tumour, the mediastinal lymph node status of the patient has profound prognostic value, and will determine subsequent treatment and possible inclusion in a neoadjuvant trial. The roles of mediastinoscopy and computed tomography (CT) remain controversial. In 1989, our department conducted a retrospective study of the value of mediastinoscopy in preoperative staging of bronchogenic carcinoma [1]. The sensitivity and specificity of mediastinoscopy were 91 and $100 \%$, respectively, and of CT scan 68 and $57 \%$, respectively.

In order to assess the accuracy of mediastinal lymph node staging by current new generation CT scanners and by mediastinoscopy, we prospectively studied a series of 100 patients with NSCLC, who underwent both procedures before thoracotomy.

\section{Materials and methods}

During the period April 1993 until September 1995, 100 patients with histologically proven NSCLC without distant metastases were evaluated by CT scan and cervical mediastinoscopy. There were 91 males and 9 females with a mean age of 64 (range 45-82) yrs. Fifty nine tumours were centrally located and 41 peripherally. Sixty four were right-sided and 36 left-sided. Histological examination showed: 54 squamous cell carcinomas; 23 adenocarcinomas; 20 large cell carcinomas; two mucoepidermoid tumours; and one atypical carcinoid. Mediastinal lymph node classification was performed according to NARUKe [2].

CT was performed with CT 9800 Quick or hilight Advantage scanners (GE Medical systems, Milwaukee, WI, USA), capable of high resolution, rapid data acquisition. Spiral protocols were not used. After obtaining a scout view, the mediastinum was scanned in contiguous $10 \mathrm{~mm}$ thick sections. Scanning began at the inferior portion of the thyroid gland to end at the adrenals. All scans proceeded craniocaudally. All patients 


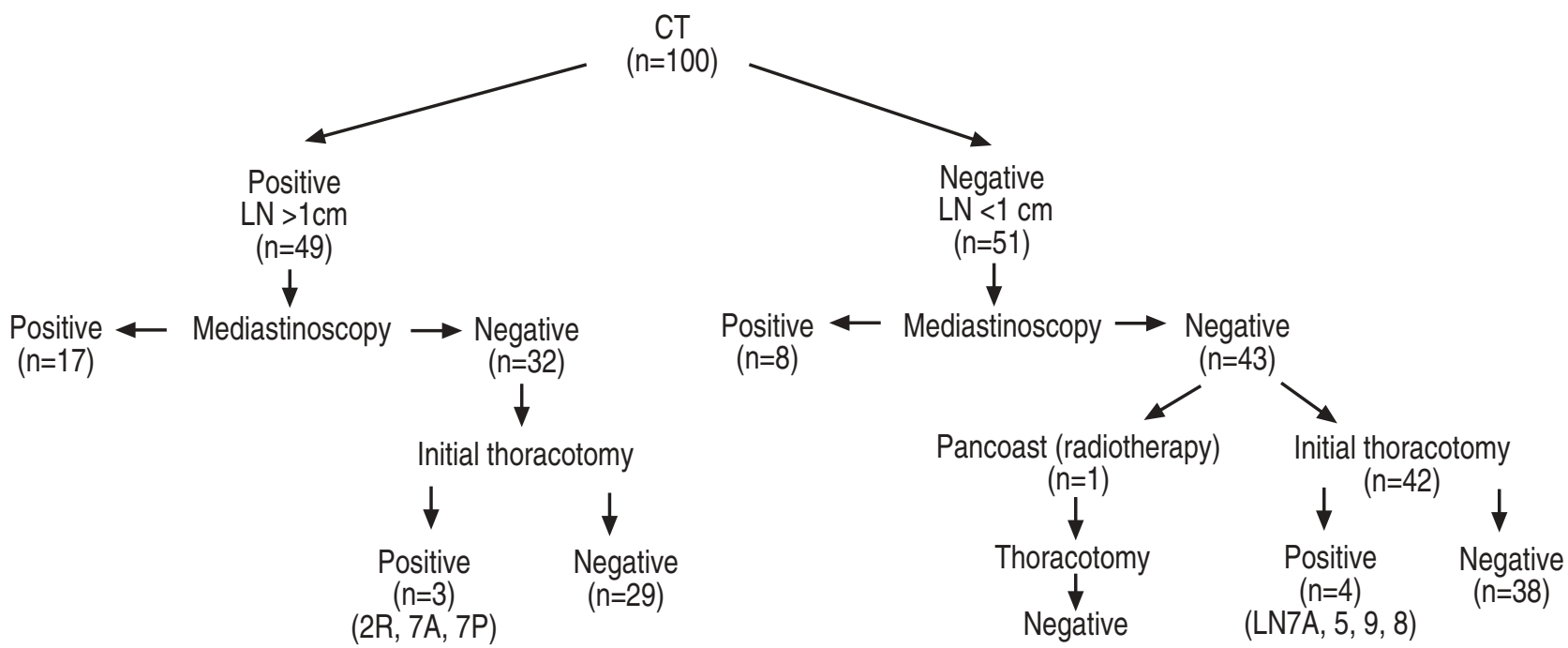

Fig. 1. - Flow chart of the study. Lymph node numbering according to NARUKE [2]. CT: computed tomography; LN: lymph node; R: right; A: anterior; P: posterior.

received $120 \mathrm{~mL}$ of $35 \%$ ionic contrast material intravenously. This was administered with a power injector in $1.0-1.5 \mathrm{~mL} \cdot \mathrm{s}^{-1}$ boluses. Two-second scans with approximately 4-8 s interscan delays were obtained with standard parameters $(120 \mathrm{KVp}, 170 \mathrm{~mA})$, with a field of view of $38 \mathrm{~cm}$. Scans were obtained at soft tissue windows 400 Hounsfield units (HU) level and $20 \mathrm{HU}$ for the mediastinum. A positive CT scan was defined as mediastinal lymph nodes larger than $1 \mathrm{~cm}$ in short axis diameter, which were accessible by mediastinoscopy and/or subsequent thoracotomy.

By cervical mediastinoscopy, all accessible lymph nodes were routinely biopsied: paratracheal No. 2, left and right; tracheobronchial No. 4, left and right; pretracheal No. 3; and anterior subcarinal No. 7 nodes, according to NARUKe [2]. Anterior mediastinoscopy was not included. The flow chart of the study is shown in figure 1 .

Of 100 patients, 74 underwent initial thoracotomy with mediastinal lymph node sampling. One patient with a Pancoast tumour had a negative mediastinoscopy, and underwent radiotherapy followed by resection of the tumour. Nonoperated patients had multilevel stage IIIA or IIIB disease.

The sensitivity, specificity, accuracy, positive and negative predictive values were calculated by the formulae presented in table 1 .

\section{Results}

There was no mortality or morbidity associated with mediastinoscopy, with the exception of one patient who had severe bronchospasm after mediastinoscopy.

Looking at the results of CT scan, there were 29 (29\%) false-positive cases, i.e. mediastinal nodes larger than 1 $\mathrm{cm}$ but not metastatic on pathological examination by mediastinoscopy and/or thoracotomy. This was more evident for centrally located tumours and squamous cell carcinoma. There were 12 (12\%) false-negative cases, i.e. mediastinal nodes smaller than $1 \mathrm{~cm}$ containing metastatic disease on pathological examination. The overall sensitivity, specificity and accuracy of CT scan were 63,57 and 59\%, respectively (table 2). CT had the lowest accuracy for left-sided and centrally located tumours.
Table 1. - Calculation of the results of computed tomography (CT) scan and mediastinoscopy

\begin{tabular}{lc}
\hline Sensitivity & $\frac{\mathrm{TP}}{\mathrm{TP}+\mathrm{FN}}$ \\
Specificity & $\frac{\mathrm{TN}}{\mathrm{TN}+\mathrm{FP}}$ \\
Accuracy & $\frac{\mathrm{TP}+\mathrm{TN}}{\mathrm{TP}+\mathrm{TN}+\mathrm{FP}+\mathrm{FN}}$ \\
$\mathrm{PPV}$ & $\frac{\mathrm{TP}}{\mathrm{TP}+\mathrm{FP}}$ \\
$\mathrm{NPV}$ & $\frac{\mathrm{TN}}{\mathrm{TN}+\mathrm{FN}}$ \\
\hline
\end{tabular}

PPV: positive predictive value; NPV: negative predictive value; TP: true-positive; TN: true-negative; FP: false-positive; FN: false-negative.

Table 2. - Results of computed tomography (CT) scan

\begin{tabular}{lccccc}
\hline & $\begin{array}{c}\text { Sensitivity } \\
\%\end{array}$ & $\begin{array}{c}\text { Specificity } \\
\%\end{array}$ & $\begin{array}{c}\text { Accuracy } \\
\%\end{array}$ & $\begin{array}{c}\text { PPV } \\
\%\end{array}$ & $\begin{array}{c}\text { NPV } \\
\%\end{array}$ \\
\hline Total & 63 & 57 & 59 & 41 & 77 \\
SQ & 69 & 51 & 56 & 31 & 84 \\
AD & 63 & 60 & 61 & 46 & 75 \\
LC & 60 & 90 & 75 & 86 & 69 \\
Central & 68 & 43 & 53 & 42 & 70 \\
Peripheral & 50 & 74 & 68 & 39 & 82 \\
Right & 68 & 60 & 63 & 47 & 78 \\
Left & 50 & 39 & 53 & 29 & 74 \\
2L & 0 & 100 & 97 & 0 & 97 \\
2R & 50 & 95 & 90 & 56 & 94 \\
4L & 0 & 99 & 93 & 0 & 94 \\
4R & 60 & 86 & 83 & 35 & 94 \\
7A & 47 & 83 & 77 & 37 & 88 \\
\hline
\end{tabular}

Calculations according to the formulae in table 1. Lymph node numbering according to NARUKE [2]. SQ: squamous; AD: adenocarcinoma; LC: large cell carcinoma; L: left; R: right; A: anterior; PPV: positive predictive value; NPV: negative predictive value. 
Table 3. - Results of mediastinoscopy

\begin{tabular}{lccccc}
\hline & $\begin{array}{c}\text { Sensitivity } \\
\%\end{array}$ & $\begin{array}{c}\text { Specificity } \\
\%\end{array}$ & $\begin{array}{c}\text { Accuracy } \\
\%\end{array}$ & $\begin{array}{c}\text { PPV } \\
\%\end{array}$ & $\begin{array}{c}\text { NPV } \\
\%\end{array}$ \\
\hline Total & 89 & 100 & 97 & 100 & 96 \\
SQ & 92 & 100 & 98 & 100 & 98 \\
AD & 80 & 100 & 96 & 100 & 95 \\
LC & 90 & 100 & 95 & 100 & 91 \\
Central & 95 & 100 & 98 & 100 & 98 \\
Peripheral & 72 & 100 & 95 & 100 & 94 \\
Right & 86 & 100 & 95 & 100 & 94 \\
Left & 100 & 100 & 100 & 100 & 100 \\
2L & 100 & 100 & 100 & 100 & 100 \\
2R & 90 & 100 & 99 & 100 & 99 \\
4L & 100 & 100 & 100 & 100 & 100 \\
4R & 100 & 100 & 100 & 100 & 100 \\
7A & 87 & 100 & 98 & 100 & 97 \\
\hline Cacul & & & & &
\end{tabular}

Calculations according to the formulae in table 1. Lymph node numbering according to NARUKe [2]. For definitions see legend to table 2 .

Looking at the individual mediastinal lymph node stations, CT had the lowest sensitivity and accuracy for subcarinal lymph nodes No. 7. Due to the absence of true-positive $2 \mathrm{~L}$ and $4 \mathrm{~L}$ lymph nodes described on CT scan, the sensitivity dropped to $0 \%$ for these locations (table 2).

Of 100 mediastinoscopies, 25 (25\%) were positive, i.e. metastatic nodes were found on pathological examination. Of these, there were seven patients with positive contralateral mediastinal nodes (N3). There were 75 negative mediastinoscopies, i.e. no malignant cells were found on histopathological examination of the nodes which were biopsied by mediastinoscopy. Of the 75 negative mediastinoscopies, 74 underwent initial thoracotomy with mediastinal node sampling. One patient with a Pancoast tumour underwent radiotherapy followed by thoracotomy. Out of 75 thoracotomies, there were seven with positive mediastinal nodes. Of these, three could have been detected by mediastinoscopy, so these three were false-negative mediastinoscopies. Seventy two had negative nodes accessible by mediastinoscopy, and these were true-negative mediastinoscopies. The overall sensitivity, specificity and accuracy of mediastinoscopy were 89, 100 and 97\%, respectively (table 3).

\section{Discussion}

Precise mediastinal lymph node staging in otherwise operable NSCLC is necessary, because, on the one hand, it limits the number of unnecessary thoracotomies, and, on the other, it gives the optimal chance to a patient with potentially curable disease. Accuracy of CT in this study was $59 \%$ and of mediastinoscopy $97 \%$. There were $12 \%$ false-negative cases on CT scan, which means that an unnecessary thoracotomy could have been performed in these cases. On the other hand, CT had 29\% falsepositive cases, which means that these patients, with potentially resectable lesions, could have lost the opportunity of resection.

In several series of patients with N2 disease who underwent thoracotomy without selection by mediastinoscopy, overall survival was no more than $10 \%$ [3]. Mediastinoscopy was first described by CARLENS [4] in 1959, who proposed a cervical approach, and then by McNeILL and
Chamberlain [5] in 1966, who proposed an anterior approach. LuKE et al. [6] described 1,000 patients who underwent mediastinoscopy during the period 1979-1984 with a negligible morbidity and mortality. Mediastinoscopy showed positive histological results in $29.6 \%$ of patients and so was found to be a valuable tool in selecting patients for operation.

With the introduction of CT scanning, better visualization of the mediastinum became possible. However, several studies demonstrated that enlarged glands on CT scanning are not necessarily metastatic [7-13]. It was shown that histological proof is mandatory before a patient is judged inoperable [8]. In the present study, $59 \%$ of mediastinal lymph nodes larger than $1 \mathrm{~cm}$ on CT scanning were not found to be metastatic on pathological examination.

Many studies have evaluated the global accuracy of $\mathrm{CT}$ in the staging of mediastinal nodal status in lung cancer [14-23]. Some of these studies have reported a high sensitivity, ranging $88-94 \%[14,15]$, values that are equivalent to the sensitivity obtained by mediastinoscopy $[6,24,25]$. However, in the prospective study by McKenna et al. [21], CT could not detect $40 \%$ of all nodal metastases.

In 1987, PATTERSON et al. [26] reported a prospective study in 84 patients comparing chest radiography, CT, magnetic resonance imaging and mediastinoscopy as staging modalities to assess mediastinal node status. Mediastinoscopy had the highest accuracy and was recommended as a routine staging procedure in patients with bronchogenic carcinoma. STAPLES et al. [22] reported a study of 151 patients comparing results of CT scan with mediastinoscopy in the staging of bronchogenic carcinoma. Biopsies of accessible stations were taken at mediastinoscopy, followed by nodal sampling at thoracotomy. CT scan had a sensitivity of $79 \%$ and a specificity of $65 \%$. The lower sensitivity in the present study can be explained by the use of a diameter of $1 \mathrm{~cm}$ in the long axis as a criterion to distinguish normal from abnormal nodes. In the study by STAPLES et al. [22], when a short axis of greater than $1 \mathrm{~cm}$ was used as the criterion for abnormality, the sensitivity dropped to $61 \%$. They, therefore, advocated the continued use of mediastinoscopy in the evaluation of possible N2 disease, even after a negative CT. A short axis diameter of 1 $\mathrm{cm}$, as used in the present study, seems to reflect the clinical reality $[27,28]$.

An important factor for accurate prediction of nodal status is the proportion of normal-sized metastatic nodes $[23,29]$. In the present study, $24 \%$ of all lymph nodes less than $1 \mathrm{~cm}$ in short axis diameter were metastatically involved by tumour. This confirms the results presented by Vogel et al. [30], who emphasized the importance of tumour typing to the proportion of metastatic normal-sized nodes.

In the study by Bollen et al. [31], assessing the interobserver variability of CT in determining nodal status in NSCLC, four experienced radiologists reviewed the CT scans of 147 patients. They concluded from the large interobserver variability and low sensitivity (40-69\% with the $1 \mathrm{~cm}$ criterion, and $28-56 \%$ with $1.5 \mathrm{~cm}$ criterion), that a negative result of CT scan regarding mediastinal lymph nodes does not eliminate the need for mediastinoscopy or mediastinal exploration at the time of thoracotomy. 
In a review on staging of lung cancer, MiLler et al. [32] stated that CT scan is frequently misleading, having a specificity of $89 \%$ and a sensitivity of only $71 \%$. The most accurate prethoracotomy method of assessing N2 and N3 disease remains mediastinoscopy. These authors even stated that they do not routinely use CT scanning but instead employ mediastinoscopy in every case to screen for nodal disease.

In 1992, McLoud et al. [33] reported a prospective study in 143 patients to determine the accuracy of CT in the evaluation of individual mediastinal nodes. All patients underwent surgical staging by mediastinoscopy alone or mediastinoscopy and thoracotomy. The sensitivity of $\mathrm{CT}$ for mediastinal nodes on a per patient basis was $64 \%$ with a specificity of $62 \%$. The overall sensitivity of CT for all the lymph node groups sampled was $44 \%$. More specifically, for nodal station 7 , sensitivity was only $25 \%$ and specificity $91 \%$. In contrast, we found a lower specificity of $83 \%$ for lymph node station 7 , but a higher sensitivity $(47 \%)$.

The results of our previous retrospective study [1] and the current prospective study are very similar. Accuracy of $\mathrm{CT}$ is around $60 \%$ and of mediastinoscopy $95 \%$.

In centres where neoadjuvant therapy is given for $\mathrm{N} 2$ or even $\mathrm{N} 3$ disease, it is clear that CT scanning alone is insufficient for precise mediastinal lymph node staging and, at present, histological proof by mediastinoscopy or other invasive means should be required for inclusion in such a trial [34].

This probably increases overall costs and this specific issue was addressed in a multicentre Canadian trial, reported in 1995 [35]. In this randomized controlled study, 685 patients with apparently operable, suspected or proven NSCLC underwent either mediastinoscopy or CT scanning. Depending on the presence or absence of mediastinal nodes greater than $1 \mathrm{~cm}$, patients in the CT group either underwent mediastinoscopy or proceeded directly to thoracotomy.

The primary outcome was thoracotomy without cure, defined as unresectable tumours, incomplete resection or recurrent disease. Secondary outcome included cost of the two strategies. The relative risk for thoracotomy without cure associated with being in the CT group was 0.95 . However, the relative risk of death from lung cancer in this group was 1.05 , none of these differences being significant. There was a nonsignificant trend to higher overall costs in the mediastinoscopy group. The conclusion was that $\mathrm{CT}$ produces the same number of, or fewer, unnecessary thoracotomies, in comparison with performing mediastinoscopies in all patients without regard to the size of the mediastinal lymph nodes. However, in this study, only $44 \%$ of patients randomized to the mediastinoscopy group had four or more lymph nodes sampled during mediastinoscopy. In $31 \%$ of patients who underwent thoracotomy after a negative mediastinoscopy, no N2 nodes were sampled. The false-negative rate and accuracy of mediastinoscopy were not reported, and this could have influenced the final results. As patients were included from 1987 to 1990 , the issue of neoadjuvant therapy was not specifically addressed.

In our opinion, the optimal approach to mediastinal staging of otherwise operable NSCLC includes both CT scanning and mediastinoscopy, certainly in centres where neoadjuvant therapy is considered for $\mathrm{N} 2$ or N3 disease.
Even a negative mediastinoscopy provides important information to the surgeon, especially about contralateral lymph nodes, and determines operative strategy during thoracotomy.

The policy of routine mediastinoscopy probably increases overall cost in comparison to a more selective attitude, where mediastinoscopy is not performed in patients with a negative CT. In this respect, when cost is a major concern and in centres where neoadjuvant therapy is not given, mediastinoscopy can be omitted when there are no enlarged lymph nodes on CT scan, especially in a peripheral squamous cell carcinoma, where mediastinal lymph node involvement is less likely.

In conclusion, our study shows that even with current new generation computed tomography scanners, sensitivity and specificity remain low. By looking at individual lymph node stations, accuracy of computed tomography was lowest for subcarinal lymph nodes. These should be routinely sampled during mediastinoscopy, which has a high accuracy and specificity.

\section{References}

1. Van Schil PEY, Van Hee RHGG, Schoofs ELG. The value of mediastinoscopy in preoperative staging of bronchogenic carcinoma. J Thorac Cardiovasc Surg 1989; 97: 240-244.

2. Naruke T. Lymph node mapping and curability at various levels of metastasis in resected lung cancer. $J$ Thorac Cardiovasc Surg 1978; 76: 832-839.

3. Pearson FG, Delarue NC, Ellves R, Todd TRJ, Cooper JD. Significance of positive superior mediastinal nodes identified at mediastinoscopy in patients with resectable cancer of the lung. J Thorac Cardiovasc Surg 1982; 83: $1-11$.

4. Carlens E. Mediastinoscopy: a method for inspection and tissue biopsy in the superior mediastinum. Dis Chest 1959; 36: 343-352.

5. McNeill TM, Chamberlain JM. Diagnostic anterior mediastinoscopy. Ann Thorac Surg 1966; 2: 532-539.

6. Luke WP, Todd TRJ, Cooper JD. Prospective evaluation of mediastinoscopy for assessment of carcinoma of the lung. J Thorac Cardiovasc Surg 1986; 91: 53-56.

7. Breyer RH, Karstaedt N, Mills SA, et al. Computed tomography for evaluation of mediastinal lymph nodes in lung cancer: correlation with surgical staging. Ann Thorac Surg 1984; 38: 215-220.

8. Brion JP, Depauw L, Kuhn G, et al. Role of computed tomography and mediastinoscopy in preoperative staging of lung carcinoma. J Comput Assist Tomogr 1985; 9: 480-484.

9. Daly BD, Faling LJ, Pugatch RD. Computed tomography: an effective technique for mediastinal staging in lung cancer. J Thorac Cardiovasc Surg 1984; 88: 486-494.

10. Imhof E, Perruchoud AP, Ian KG, Hasse J, Heitz M, Graedel E. Mediastinal staging of bronchial carcinoma: can computed tomography replace mediastinoscopy? Respiration 1985; 48: 251-260.

11. Lewis JW, Madrazo BL, Gross SC, et al. The value of radiographic and computed tomography in the staging of lung carcinoma. Ann Thorac Surg 1982; 34: 553-558.

12. Richey HM, Matthews JI, Helsel RA, Cable H. Thoracic CT scanning in the staging of bronchogenic carcinoma. Chest 1984; 85: 218-221.

13. Unruh H, Chiu RC. Mediastinal assessment for staging 
and treatment of carcinoma of the lung. Ann Thorac Surg 1986; 41: 224-229.

14. Faling LJ, Pugatch RD, Jung Legg Y. Computed tomography scanning of the mediastinum in the staging of bronchogenic carcinoma. Am Rev Respir Dis 1981; 124: 690-695.

15. Osborne DR, Korobkin M, Ravin C, et al. Comparison of plain radiography, conventional tomography and computed tomography in detecting lymph node metastasis from lung carcinoma. Radiology 1982; 142: 157-161.

16. Baron RL, Levitt RG, Sagel SS, White MJ, Roger CL, Marberger JP. Computed tomography in the preoperative evaluation of bronchogenic carcinoma. Radiology 1982; 145: 727-732.

17. Matthews JI, Richey HM, Helsel RA, Grishkin BA. Thoracic computed tomography in the preoperative evaluation of primary bronchogenic carcinoma. Arch Intern Med 1987; 147: 449-453.

18. Friedman PJ, Feigin DS, Liston SE, et al. Sensitivity of chest radiography, computed tomography and gallium scanning in metastasis of lung carcinoma. Cancer 1984; 54: 1300-1306.

19. Glazer GM, Orringer MB, Gross BH, Quint LE. The mediastinum in non-small cell lung cancer. CT-surgical correlation. Am J Roentgenol 1984; 142: 1101-1105.

20. Libshitz HL, McKenna RJ, Haynie TP, McMurtney MJ, Mountain C. Mediastinal evaluation in lung cancer. Radiology 1984; 151: 295-299.

21. McKenna RJ, Libshitz HI, Mountain CE, McMurtney MJ. Roentgenographic evaluation of mediastinal nodes for preoperative assessment in lung cancer. Chest 1985; 88: 206-210.

22. Staples CA, Myller NL, Miller RR, Evans KG, Nelems B. Mediastinal nodes in bronchogenic carcinoma: comparison between CT and mediastinoscopy. Radiology 1988; 167: 367-372.

23. Gross BH, Glazer GM, Orringer MB, Spizarny DL, Flint A. Bronchogenic carcinoma metastatic to normal-sized lymph nodes: frequency and significance. Radiology 1988; 166: 71-74.

24. Pearson FG, Nelems JM, Henderson RD, Delarue NC. The role of mediastinoscopy in the selection of treatment for bronchogenic carcinoma with involvement of superior mediastinal lymph nodes. J Thorac Cardiovasc Surg 1972; 64: 382-387.

25. Jolly PC, Wei L, Anderson RP. Anterior and cervical mediastinoscopy for determination and predicting resectability in lung cancer. J Thorac Cardiovasc Surg 1980; 79: 366-371.

26. Patterson GA, Ginsberg RJ, Poon PY, et al. A prospective evaluation of magnetic resonance imaging, computed tomography, and mediastinoscopy in the preoperative assessment of mediastinal node status in bronchogenic carcinoma. J Thorac Cardiovasc Surg 1987; 94: 679684.

27. Lewis JW, Pearlberg J, Beute GH, et al. Can computed tomography of the chest stage lung cancer? Yes and no. Ann Thorac Surg 1990; 49: 591-596.

28. Kiyono K, Sone S, Sakai F, Imai Y, et al. The number and size of normal mediastinal lymph nodes: a postmortem study. Am J Roentgenol 1988; 150: 771-776.

29. Whittlesey DN. Prospective computed tomographic scanning in the staging of bronchogenic cancer. $J$ Thorac Cardiovasc Surg 1988; 95: 876-882.

30. Vogel R, Daschner H, Lenz J, Schafer R. Uber den Zusammenhang von Lymphknoten Grösse und metastatischem Befall der Lymphknoten bei Bronchialkarzinom. Langenbecks Arch Chir 1990; 375: 141-144.

31. Bollen EC, Goei R, van't Hof-Grootenboer BE, Versteege $\mathrm{CW}$, Engelshove HA, Lamers RJ. Interobserver variability and accuracy of computed tomographic assessment of nodal status in lung cancer. Ann Thorac Surg 1994; 58: 158-162.

32. Miller JD, Gorenstein LA, Patterson GA. Staging: the key to rational management of lung cancer. Ann Thorac Surg 1992; 53: 170-178.

33. McLoud TC, Bourgouin PM, Greenberg RW, et al. Bronchogenic carcinoma: analysis of staging in the mediastinum with $\mathrm{CT}$ by correlative lymph node mapping and sampling. Radiology 1992; 182: 319-323.

34. Edelman MJ, Gandara DR, Roach III M, Benfield JR. Multimodality therapy in stage III non-small cell lung cancer. Ann Thorac Surg 1996; 61: 1564-1572.

35. The Canadian Lung Oncology Group. Investigation for mediastinal disease in patients with apparently operable lung cancer. Ann Thorac Surg 1995; 60: 1382-1389. 